\title{
Differential Response to the Cholinergic Agonist Arecoline among Different Cognitive Modalities in Alzheimer's Disease
}

Kathleen C. Raffaele, Ph.D., Sanjay Asthana, M.D., Annamaria Berardi, Ph.D., James V. Haxby, Ph.D., P. Pearse Morris, M.D., Mark B. Schapiro, M.D., and Timothy T. Soncrant, M.D.

Nine patients with possible or probable dementia of the Alzheimer type were tested on nine cognitive tests prior to (two times) and during continuous intravenous administration of five different doses of the muscarinic cholinergic agonist arecoline $(1,4,16,28$, and $40 \mathrm{mg} /$ day $)$. The present analysis examined whether improvement on cognitive testing for each patient during arecoline treatment was most likely to occur at the same dose for all tests or whether different test scores improved at different doses of arecoline. Results indicated there were significant differences among tests in the dose at which most patients showed improved cognitive performance. These differences may have therapeutic significance, as verbal ability tended to improve at low doses of arecoline, whereas attention and visuospatial ability tended to improve at higher doses of arecoline. [Neuropsychopharmacology 15:163-170, 1996]

function in patients with Alzheimer's disease (Hollander et al. 1985; Tariot et al. 1988; Thal et al. 1989; Farlow et al. 1992; Knapp et al. 1994; Levy et al. 1994).

We recently completed a study examining cognitive performance of Alzheimer's disease patients receiving a continuous intravenous infusion of arecoline, a direct muscarinic receptor agonist (Raffaele et al. 1991; Soncrant et al. 1993). Because it has been found that not all subjects show improved performance at the same dose of a cholinergic agent and that the dose that optimizes performance may vary (Davis and Mohs 1982), we attempted to determine an optimal dose of arecoline for each individual patient. Arecoline was administered at five different dosing rates in an open-phase rising-dose study. Replication of open-phase results was then attempted during a double-blind placebo-controlled administration of each patient's "best dose," that is, the dose that optimized that patient's overall cognitive performance (Soncrant et al. 1993). Significant improvements were seen on two cognitive tests during the rising-dose study: selective reminding (a verbal memory 
task) and figure copying (a visuospatial task with no memory component). During the replication study, the performance improvement on the selective reminding task was repeated, but performance on the figure-copying task was not significantly improved. Because of this discrepancy between the results of the rising-dose study and the double-blind replication study, and noting an apparent difference in the dose at which performance improved on the two tasks during the risingdose administration, we wished to examine whether or not the dose at which performance improved varied among different cognitive tasks. We also sought to determine whether performance on tasks based on similar cognitive functions (such as visual, verbal, or attentional) improved at similar doses.

\section{METHODS}

The overall procedures and results for the drug treatment study have been previously published (Soncrant et al. 1993). Briefly, subjects were nine carefully screened healthy subjects (five men and four women; age range 50-81 [mean $63.1 \pm 9.4]$ ). All subjects were medication free. All were diagnosed with possible (isolated memory impairment) or probable Alzheimer's disease according to NINCDS/ADRDA criteria (McKhann et al. 1984), and eight of nine subsequently met all criteria for probable Alzheimer's disease. Mini-Mental State Examination (Folstein et al. 1975) scores ranged from 15 to 26 (mean $23.0 \pm 3.4$ ). Consent to participate in this investigation was obtained from each patient and/or from an empowered relative. All studies were performed on an inpatient basis. The protocol was approved by the $\mathrm{Na}$ tional Institute on Aging Institutional Review Board (protocol number 88-AG100).

Arecoline hydrobromide (Regis Chemical, Morton Grove, IL), dissolved in normal saline, was administered by continuous intravenous infusion over the course of the study, using CADD-1 Ambulatory infusion pumps (Pharmacia Deltec, St. Paul, MN). During all infusion periods, methscopolamine bromide (Upjohn, Kalamazoo, MI), a muscarinic receptor antagonist that does not enter the brain, was administered at a dose of $2.5 \mathrm{mg}$ orally every 8 hours (to block the peripheral autonomic actions of arecoline).

Arecoline was administered by continuous intravenous infusion at doses of $0.5,1,2,4,8,16,22,28,34$, and $40 \mathrm{mg} /$ day. Doses were escalated on a daily basis following completion of psychological and/or physiological testing. Neuropsychological testing was conducted twice prior to the initiation of drug administration ( 3 days and 3 hours prior to initiation of arecoline treatment), during the infusion of every other dose $(1,4,16,28$, and $40 \mathrm{mg} /$ day), and twice after cessation of drug treatment (sessions were separated by 1 day without testing and were separated from the drug treatment period by at least 1 week).

A total of nine cognitive tests were administered during two 1- to 2-hour test sessions conducted between 9:00 A.M. and 1:00 P.M. Tests administered were as follows: (1) calculation ability (ability to correctly perform mathematical operations of varying difficulty); (2) visual and verbal continuous recognition memory (ability to recognize faces or words previously presented during sequential presentation on a computer screen [Berardi et al. 1991]); (3) figure-copying (ability to copy accurately a series of geometric drawings [Haxby et al. 1985]); (4) Stroop color-word interference (a test of attention [Golden 1978]); (5) verbal fluency (letter [FAS] and category fluency [Benton and Hamsher 1976; Butters et al. 1987]); (6) the Token test (a test of ability to follow verbal commands [Boller and Vignolo 1966]); (7) Benton Visual Retention Test (a test of ability to accurately draw a series of line drawings from memory [Benton 1974]); (8) Digit/Symbol Substitution Test (a test of attention/concentration [Wechsler 1955]); (9) Buschke Selective Reminding Test (a test of verbal memory [Buschke 1973]). Details of the tests and their administration have been described previously (Soncrant et al. 1993).

For each patient, a "best dose" was determined for each task by selecting the dose of arecoline on which that patient achieved his or her best performance on that task. These individual "best doses" were then compared across tasks using one-way analysis of variance (ANOVA) and least significant difference (LSD) multiple comparison procedures (SAS Institute 1988). A total of 16 score parameters were included in this analysis: Benton Visual Retention Test-total errors (Benton Errors); Buschke Selective Reminding-total recall (Buschke TR) and long-term recall (Buschke LTR); Calculationstotal number correct; category fluency-total words named; figure copying-error score; Digit symbol test-number correctly completed; FAS verbal letter fluency-total words named (FAS); Stroop interference task-words, colors, and interference colors named; Token Task-number correct; continuous recognition memory - verbal long-term memory (CR-Word Long), verbal short-term memory (CR-Word Short), visual long-term memory (CR-Face Long), and visual shortterm memory (CR-Face Short).

\section{RESULTS}

There was a significant overall effect of test $(F=2.57$, $p=.0022, \mathrm{df}=15,128$ ), indicating (1) that the dose at which performance improved most differed among tests, and (2) that this difference was not random among subjects but that performance on a particular test improved at similar doses across subjects. Using the 
multiple comparison procedure, significant differences between specific tests were identified (see Figure 1). In particular, performance on tests involving verbal function (verbal memory, verbal comprehension, and verbal fluency) improved at low doses of arecoline (mean doses ranging from 4.3 to $12.7 \mathrm{mg} /$ day), and performance on tests involving attentional function (digit/ symbol substitution and Stroop interference) improved at higher doses of arecoline (mean dose of $26.7 \mathrm{mg} /$ day for both tasks). Tests involving visuospatial function also improved at higher doses of arecoline (mean doses ranging from 19.7 for Benton retention test to 26.7 for figure copying).

\section{Verbal Tasks}

The mean best doses for all verbal tasks, other than the continuous recognition tasks, were tightly clustered at the lower end of the dose range. The mean best dose ranged from $4.3 \mathrm{mg}$ /day for Buschke total recall to 14.7 $\mathrm{mg} /$ day for Stroop Words. As there was a significant overall improvement in performance on the Buschke Selective Reminding task (Buschke TR) at these doses
( $p<.05$ vs. baseline at $4 \mathrm{mg} /$ day; see Soncrant et al. 1993), this clustering does not simply represent impairment of performance by arecoline at the higher dose levels (there was in fact no significant impairment of baseline performance at any dose level). The two verbal fluency tasks, FAS and category fluency, which had identical designs and differed only in the type of verbal fluency measured (letter or category fluency), had almost identical mean best doses ( 12.7 and $12.3 \mathrm{mg} /$ day, respectively) which would be unlikely if the differences in mean best dose across tasks were simply a random finding.

The "verbal" portion of the continuous recognition task (CR Word) had mean best doses for both the longand short-term memory components that were not as low as the mean best doses found for other verbal tasks. This result may be due to a general lack of sensitivity of the continuous recognition test to arecoline under the testing conditions (mean best doses for the two shortterm memory measures for this task were not significantly different from the mean best dose for any other task; this would imply a lack of drug effect on at least this component of the task). It is also possible that the higher mean best doses are due to a visuospatial com-

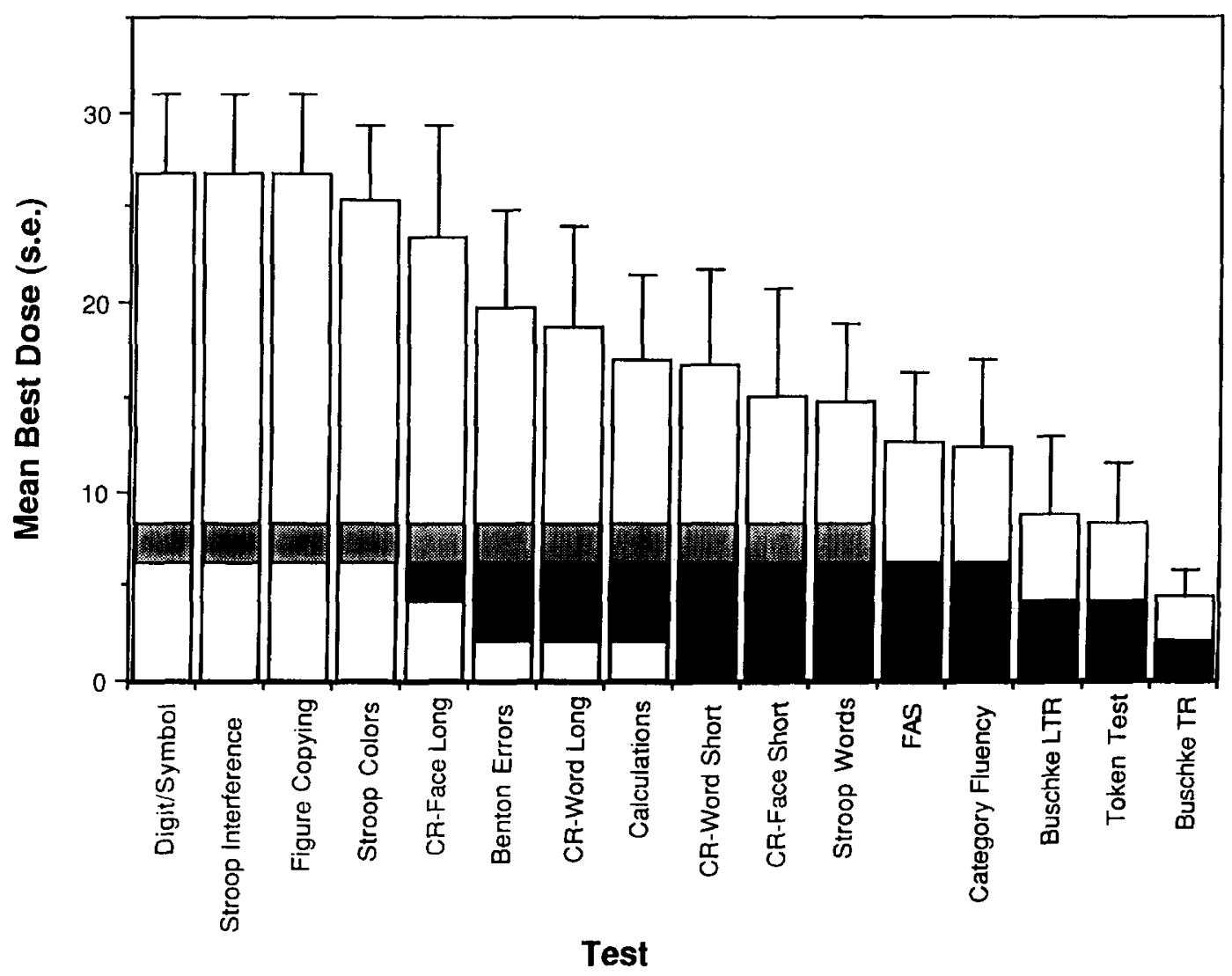

Figure 1. Mean best dose for each test (error bars indicate standard error). Shaded bars indicate significance groupings (i.e., groups with the same shade bars are not significantly different from each other). 
ponent of the "words" continuous recognition task, because it involves reading the word (Peterson et al. 1988).

\section{Attention and Visuospatial Tasks}

Overall, visuospatial tasks improved at a higher range of doses than did verbal tasks. For example, the mean best doses were 26.7 for figure copying and 19.7 for Benton Visual Retention. There were no visuospatial tasks with mean best doses at the low end of the dose range.

The mean best doses for the two attentional tasks were toward the top of the dose range (mean best dose was $26.7 \mathrm{mg} /$ day for both digit/symbol substitution and stroop interference) but did not include the highest dose administered ( $40 \mathrm{mg} /$ day). No mean best dose was higher than $28 \mathrm{mg} /$ day (the second highest administered dose). The improvement in attention and visuospatial function found at high doses is unlikely to be due solely to a practice effect, for the following reasons. (1) Although the improvement occurred toward the end of testing, it was not greatest at the highest tested dose. In fact, the difference between the calculated mean best dose for figure copying, stroop interference, and digit symbol substitution $(26.7 \mathrm{mg} / \mathrm{d})$ and the highest administered dose $(40 \mathrm{mg} / \mathrm{d})$ was 13.3 , greater than the least significant difference of 12.4 (by the LSD multiple comparison procedure). (2) Mean post-test scores were not different from baseline scores for Stroop interference or figure copying; there was some improvement over baseline in post-test scores for digit-symbol substitution, but the improvement was less than that achieved on the highest arecoline dose (Soncrant et al. 1993). (3) Although similar tests were used, a similar distribution of mean best dose levels was not seen in a second study in which physostigmine (which acts by a different mechanism, inhibiting acetylcholinesterase as opposed to directly activating receptors) was given during a similar rising dose administration period. If the effects seen following arecoline administration were due solely to a practice effect, the same tests should have been subject to practice effects, and therefore have shown the highest mean best dose, in the physostigmine study. This was not the case (Asthana et al. in press).

\section{Memory Tasks}

There was no clear best dose range for memory as a unitary function. Within a functional category (such as visuospatial or verbal), tasks that also included a memory component tended to improve most at the lower end of the best dose range for that function. Thus, Buschke total recall (mean best dose $4.3 \mathrm{mg} /$ day) and long-term recall (mean best dose $8.7 \mathrm{mg} /$ day) had lower mean best doses than the verbal fluency tasks. The mean best dose for the token task ( $8.3 \mathrm{mg} /$ day) was similar to that for Buschke total recall. Within the group of visuospatial tasks, the Benton Visual Retention Task, a visual memory task, had a lower mean best dose $(19.7 \mathrm{mg} /$ day) than did the figure-copying task (mean best dose $26.7 \mathrm{mg} /$ day), which included no memory component. It is possible that the overall cognitive environment of a task, such as the verbal or visuospatial context, is more critical in determining the optimal level of cholinergic activation, and that other aspects of task, such as memory, may lead to a finer level of distinction within the general range.

\section{DISCUSSION}

These results demonstrate that during the administration of arecoline by continuous intravenous infusion to patients with possible or probable Alzheimer's disease, different aspects of cognition were improved by differing doses of arecoline. These findings may in part explain the variability of the dose-response curve for cholinergic drugs among individuals, and perhaps the mixed results on effectiveness of cholinergic drugs in treating symptoms of Alzheimer's disease (Becker and Giacobini 1988; Brinkman and Gershon 1983). In addition, they indicate that even finely tuned cholinergic stimulation may not achieve simultaneous optimization of all cognitive modalities.

The limitations in our original arecoline studies, especially the open design during the escalating-dose phase and the potential for confounding by practice effects (especially with regard to tasks with a higher mean best dose), accentuate the need for replication of these results before firm conclusions can be made based on these findings. However, the present findings may explain the failure to replicate, during double-blind testing, the significant improvement found in figure copying during an open escalating-dose study (see Soncrant et al. 1993 for details). The mean optimal dose used during the replication study $[7.7 \pm 6.3$ (sd) $\mathrm{mg} /$ day] was within the range of maximal improvement for verbal functions, particularly verbal memory, but substantially lower than that producing maximal improvement on visuospatial tests.

One previous study investigating arecoline administration to Alzheimer's patients demonstrated an improvement in picture recognition following a dose of $2 \mathrm{mg} /$ hour (the mean best dose for visuospatial tasks in our study was $26.7 \mathrm{mg}$ /day, equivalent to $1.1 \mathrm{mg} /$ hour) and an impairment in category retrieval (similar to our verbal fluency measure) following the same $2 \mathrm{mg}$ /hour dose (Sunderland et al. 1988; Tariot et al. 1988). Qualitative observer ratings of verbal expressiveness and word 
finding demonstrated a significant improvement in patients during the $1 \mathrm{mg} /$ hour arecoline infusion. Because the lowest dose administered in this study was $1 \mathrm{mg} /$ hour (a dose at which category retrieval was not changed from baseline), there was no dose comparable to that at which verbal ability was improved in our study (4.3-14.7 mg/day, equivalent to $0.18-0.61 \mathrm{mg} /$ hour). It is possible that these results may be interpreted as providing some support for our findings (i.e., that visuospatial tasks were improved only at a higher dose of agonist, while verbal tasks were improved at a dose ( 0.18 to $0.61 \mathrm{mg} /$ hour) lower than that administered in the Tariot et al. (Tariot et al. 1988) study (1 mg/hour), but impaired or unchanged at higher doses of arecoline).

Other studies have demonstrated differences in the level of cholinergic activation required for physiological functions (e.g., heart rate, body temperature) compared with cognitive functions (activity levels in animals, memory tests, and other cognitive tests in humans) (Ashe and Weinberger 1991; Becker and Giacobini 1988; Flicker et al. 1990; Russell et al. 1986) and differences in effective doses among similar tasks with varying task parameters (e.g., positive vs. negative reinforcement [Raffaele et al. 1990]; automated vs. manual administration [Rupniak 1992]), but clear distinctions among optimal levels of cholinergic function for specific types of cognitive functions have not been made. Although studies in animals have used many different types of task and many different cholinergic/anticholinergic agents, no clear difference in dose-response parameters for different types of cognitive tasks has been established. This failure may be due to the difficulties in comparing specific tasks and the frequent lack of doseresponse information (Fibiger et al. 1991), rather than to a true absence of a dose-response differential across task types. For example, many studies use only one drug dose; thus, even if several tasks are investigated, with some showing sensitivity and others not, it is not possible to say that there is a varying dose-response curve across tasks because it is not known whether performance on unaffected tasks would or would not change with lower or higher drug doses than the one administered.

The mechanism of the apparent differential sensitivity of cognitive functions to muscarinic drugs cannot be determined based on the current study. However, evidence from other studies supports several possible mechanisms. First, there may be differences in overall cholinergic receptor concentrations among different brain regions, or variation of receptor subtypes or receptor affinity among the anatomic structures may be involved in mediating different types of cognitive functions. Differences in the distribution of receptor subtypes among brain regions have been demonstrated (Crews et al. 1986; Ashe and Weinberger 1991). Arecoline is a partial agonist with higher $M_{2}$ than $M_{1}$ receptor af- finity (Messer et al. 1989). Different concentrations of arecoline may alter the relative level of activation of $\mathrm{M}_{1}$ vs. $\mathrm{M}_{2}$ receptors (for example, different arecoline concentrations may be required to stimulate different receptor subtypes) (Freedman et al. 1988). Different patterns of relative activation may be required for optimization of different types of cognitive function. This has been shown for physiological functions (e.g., ratios of effective doses for induction of hypothermia and salivation vary among muscarinic agonists; see Freedman et al. 1990).

Second, baseline levels of acetylcholine vary among brain regions (Day et al. 1991), which might imply that in order to change the functionality of acetylcholine among different systems, different levels of stimulation are required, leading to differences in effective doses of pharmacological agent among systems.

Third, differences in the responsiveness of neurons in different brain regions to behavioral or pharmacological stimuli (Crews et al. 1986; Day et al. 1991) and of different cortical neurons to the same pharmacological stimulation (Bassant et al. 1990; Juliano et al. 1990) have been demonstrated. It has also been shown that the effects of arecoline on cerebral brain metabolism in rats vary among brain regions depending on the administered dose of arecoline, with the hippocampus showing increased activation (as measured by local cerebral glucose utilization) at lower doses of arecoline than were required to increase cortical activation (Soncrant et al. 1985). These differences in responsiveness could cause neurons in different brain regions to respond differentially to the same dose of pharmacological agent.

Fourth, there may be differences in cortical stimulation by basal forebrain neurons among different brain regions, implying differences in the levels of activation needed to promote optimal neuronal function for a specific brain region. Projections of basal forebrain neurons are highly localized to small cortical areas, and there are topographical differences in the baseline firing rate of basal forebrain neurons (Richardson and DeLong 1991), differences in firing activity related to physiological state (Woolf and Butcher 1991), and differences in acetylcholine release in the cortex in response to different behavioral or pharmacological states (Day et al. 1991). These mechanisms, individually or in concert, could account for the differences in dose-response curves among tasks shown in our data.

Our results indicate that multiple cognitive abnormalities (e.g., dysfunctions spanning both verbal and visuospatial domains) cannot be simultaneously corrected by systemic administration of cholinergic agonists. They would also imply that cholinergic therapies might be more useful earlier in the disease, when a single dominant performance deficit could be targeted. These findings also raise the question of whether cholinesterase inhibition would be a more physiologically 
relevant way to treat this disease (because the endogenous differences in stimulation would be amplified), rather than trying to treat by directly stimulating at a (perhaps inappropriate) generic level. The lack of unitary function in the cholinergic system, both as an explanation for the varying results of Alzheimer's disease treatment trials and as an exposition on the futility of treatment by simply increasing baseline cholinergic stimulation, has been discussed by several authors (Crews et al. 1986; Becker and Giacobini 1988; Durkin 1989; Sarter et al. 1990; Fibiger 1991; Fibiger et al. 1991). Our results are in agreement with their theoretical discussions and (if confirmed) perhaps provide some details of the end points achieved by differential functioning within the cholinergic system. Further studies are needed to determine whether the present findings can be replicated and whether the same types of differential dose-response curves will be found for drugs that act as cholinesterase inhibitors or whether this effect may be specific to those drugs that act directly on muscarinic receptors.

These results also raise questions about the sensitivity of the methods currently used to evaluate drug efficacy in therapeutic trials of cholinergic treatments for Alzheimer's disease. Commonly used evaluations, especially in the large multi-center trials, are based on cognitive scales or measures using a composite score derived from a variety of cognitive components (e.g., the Alzheimer's Disease Assessment Scale [Rosen et al. 1984]). Because different components of these scales may be improved on different drug doses or improvements in some components on a particular dose may be obscured by lack of improvement or impairment in other components at the same dose, drug efficacy evaluations based on these scales may need to be reassessed.

These results may also offer some insight into the functioning of the cholinergic system and its role in cognitive performance. It has previously been suggested that the cholinergic system may be important in maintaining a level of "alertness" or "cunstraints on information processing" in an organism, and that control of this "alertness" level may be important in memory and attentional function (Callaway et al. 1992). The results of this study support a somewhat different hypothesis, suggesting that optimal modulation of cognitive efficiency within different neural systems requires different concentrations of cholinergic agonists. Thus, the optimal level of functioning for the cholinergic system may be dependent upon the type of task being performed. As discussed above, this hypothesis is supported by a variety of physiological evidence, including differences in type and concentration of muscarinic receptors among brain regions, highly localized cortical projections from the basal forebrain, baseline concentrations of acetylcholine that vary among brain regions, and differences in baseline firing rate among basal forebrain neurons. These factors, in combination with the highly specific types of information and processes involved in cognitive function, argue strongly for much greater degrees of specificity and sensitivity in patterns of cholinergic stimulation than was previously thought.

\section{REFERENCES}

Ashe JH, Weinberger NM (1991): Acetylcholine modulation of cellular excitability via muscarinic receptors: Functional plasticity in auditory cortex. In Richardson RT (ed), Activation to Acquisition: Functional Aspects of the Basal Forebrain Cholinergic System. Boston, Birkhauser, pp 189-246

Asthana S, Raffaele KC, Berardi A, Greig NH, Haxby JV, Schapiro MB, Soncrant TT (1996) (in press): Treatment of Alzheimer's disease by continuous intravenous infusion of physostigmine. Alz Dis Assoc Disord

Bassant MH, Baleyte JM, Lamour Y (1990): Effects of acetylcholine on single cortical somatosensory neurons in the unanesthetized rat. Neuroscience 39:189-197

Becker RE, Giacobini E (1988): Mechanisms of cholinesterase inhibition in senile dementia of the Alzheimer type: Clinical, pharmacological, and therapeutic aspects. Drug Devel Res 12:163-195

Benton AL (1974): Revised Visual Retention Test Manual. New York, Psychological Corporation

Benton AL, Hamsher KD (1976): Multilingual Examination. Iowa City, University of Iowa

Berardi A, Haxby JV, Grady CL, Rapoport SI (1991): Asymmetries of brain glucose metabolism and memory in healthy aging. Dev Neuropsychol 7:87-97

Boller F, Vignolo LA (1966): Latent sensory aphasia in hemisphere-damaged patients: An experimental study with the Token Test. Brain 89:815-831

Brinkman SD, Gershon S (1983): Measurement of cholinergic drug effects on memory in Alzheimer's disease. Neurobiol Aging 4:139-145

Buschke H (1973): Selective reminding for analysis of memory and learning. J Verb Learn Verb Behav 12:543-550

Butters N, Granholm E, Salmon DP, Grant I (1987): Episodic and semantic memory: A comparison of amnesic and demented patients. J Clin Exp Neuropsychol 9:479-497

Callaway E, Halliday R, Naylor H (1992): Cholinergic activity and constraints on information processing. Biological Psychol 33:1-22

Crews FT, Meyer EM, Gonzales RA, Theiss C, Otero DH, Larsen K, Raulli R, Calderini G (1986): Presynaptic and postsynaptic approaches to enhancing central cholinergic neurotransmission. In Crook T, Bartus RT, Ferris S, Gershon S (eds), Treatment Development Strategies for Alzheimer's Disease. Madison, CT, Mark Powley Associates, pp 385-419

Davis KL, Mohs RC (1982): Enhancement of memory processes in Alzheimer's disease with multiple-dose intravenous physostigmine. Am J Psychiat 9:1421-1424

Day J, Damsma G, Fibiger HC (1991): Cholinergic activity in 
the rat hippocampus, cortex and striatum correlates with locomotor activity: An in vivo microdialysis study. Pharmacol Biochem Behav 38:723-729

Durkin T (1989): Central cholinergic pathways and learning and memory processes: Presynaptic aspects. Comp Biochem Physiol 93A:273-280

Farlow M, Gracon SI, Hershey LA, Lewis KW, Sadowsky CH, Dolan-Ureno J, Tacrine Study Group (1992): A controlled trial of tacrine in Alzheimer's disease. JAMA 268:2523-2529

Fibiger HC (1991): Cholinergic mechanisms in learning, memory and dementia: A review of recent evidence. Trends Neurosci 14:220-223

Fibiger HC, Damsma G, Day JC (1991): Behavioral pharmacology and biochemistry of central cholinergic neurotransmission. In Napier TC, Kalivas PW, Hanin I (eds), The Basal Forebrain. Advances in Experimental Medicine and Biology, vol 295. New York, Plenum, pp $399-414$

Flicker C, Serby M, Ferris SH (1990): Scopolamine effects on memory, language, visuospatial praxis and psychomotor speed. Psychopharmacology 100:243-250

Folstein MF, Folstein SE, McHugh PR (1975): "Mini-mental state": A practical method for grading the cognitive state of patients for the clinician. J Psychiatr Res 12:189198

Freedman SB, Harley EA, Iversen LL (1988): Relative affinities of drugs acting at cholinoceptors in displacing agonist and antagonist radioligands: The NMS/Oxo-M ratio as an index of efficacy at cortical muscarinic receptors. Br J Pharmacol 93:437-445

Freedman SB, Harley EA, Marwood RS, Patel S (1990): In vivo characterisation of novel efficacious muscarinic receptor agonists. Eur J Pharmacol 187:193-199

Geula C, Mesulam MM (1989): Cortical cholinergic fibers in aging and Alzheimer's disease: A morphometric study. Neurosci 33:469-481

Golden CJ (1978): The Stroop Color and Word Test: A Manual for Clinical and Experimental Uses. Chicago, Stoetling

Haxby JV, Duara R, Grady CL, Cutler NR, Rapoport SI (1985): Relations between neuropsychological and cerebral metabolic asymmetries in early Alzheimer's disease. J Cereb Blood Flow Metab 5:193-200

Hollander E, Davidson M, Mohs RC, Horvath TB, Davis BM, Zemishlany Z, Davis KL (1985): RS 86 in the treatment of Alzheimer's disease: Cognitive and biological effects. Biol Psychiatry 22:1067-1078

Juliano SL, Ma W, Bear MF, Eslin D (1990): Cholinergic manipulation alters stimulus-evoked metabolic activity in cat somatosensory cortex. J Comp Neurol 297:106-120

Knapp MJ, Knopman DS, Solomon PR, Pendlebury WW, Davis CS, Gracon SI, Tacrine Study Group (1994): A 30week randomized controlled trial of high-dose tacrine in patients with Alzheimer's disease. JAMA 271:985-991

Levy A, Brandeis R, Treves TA, Meshulam Y, Mawassi F, Feiler D, Wengier A, Glikfeld P, Grunwald J, Dachir S, Rabey JM, Levy D, Korczyn AD (1994): Transdermal physostigmine in the treatment of Alzheimer's disease. Alz Dis Assoc Disord 8:15-21
McGeer PL (1984): Aging, Alzheimer's disease, and the cholinergic system. Can J Physiol Pharmacol 62:741-754

McKhann G, Drachman D, Folstein M, Katzman R, Price D, Stadlan EM (1984): Clinical diagnosis of Alzheimer's disease: Report of the NINCDS-ADRDA Work Group under the auspices of Department of Health and Human Services Task Force on Alzheimer's disease. Neurol 34:939-944

Messer WS, Ellerbrock B, Price M, Hoss W (1989): Autoradiographic analyses of agonist binding to muscarinic receptor subtypes. Biochem Pharmacol 38:837-850

Peterson SE, Fox PT, Posner MI, Mintun M, Raichle ME (1988): Positron emission tomographic studies of the cortical anatomy of single-word processing. Nature 331: $585-589$

Raffaele K, Olton D, Annau Z (1990): Repeated exposure to diisopropylfluorophosphate (DFP) produces increased sensitivity to cholinergic antagonists in discrimination retention and reversal. Psychopharmacol 100:267-274

Raffaele KC, Berardi A, Asthana S, Morris P, Haxby JV, Soncrant TT (1991): Effects of long-term continuous infusion of the muscarinic cholinergic agonist arecoline on verbal memory in dementia of the Alzheimer type. Psychopharmacol Bull 27:315-319

Richardson RT, DeLong MR (1991): Functional implications of tonic and phasic activity changes in nucleus basalis neurons. In Richardson RT (ed), Activation to acquisition: Functional aspects of the basal forebrain cholinergic system. Boston, Birkhauser, pp 135-166

Rosen WG, Mohs RC, Davis KL (1984): A new rating scale for Alzheimer's disease. Am J Psychiatry 141:1356-1364

Roth M (1986): The association of clinical and neurological findings and its bearing on the classification and aetiology of Alzheimer's disease. Br Med Bull 42:42-50

Rupniak NMJ (1992): Profile of cholinomimetic drugs in primates: Status of screens for potential Alzheimer therapies. Drug Devel Res 27:77-88

Russell RW, Smith CA, Booth RA, Jenden DJ, Waite JJ (1986): Behavioral and physiological effects associated with changes in muscarinic receptors following administration of an irreversible cholinergic agonist (BM 123). Psychopharmacol 90:308-315

Sarter M, Bruno JP, Dudchenko P (1990): Activating the damaged basal forebrain cholinergic system: Tonic stimulation versus signal amplification. Psychopharmacol 101:1-17

SAS Institute, Inc. (1988): SAS/STAT Release 6.03 Edition, Cary, NC, SAS Institute, Inc.

Soncrant TT, Holloway HW, Rapoport SI (1985): Arecolineinduced elevations of regional cerebral metabolism in the conscious rat. Brain Res 347:205-216

Soncrant TT, Raffaele KC, Asthana S, Berardi A, Morris PP, Haxby JV (1993): Memory improvement without toxicity during chronic low dose intravenous arecoline in Alzheimer's disease. Psychopharmacology 112:421-427

Sunderland T, Tariot PN, Newhouse PA (1988): Differential responsivity of mood, behavior, and cognition to cholinergic agents in elderly neuropsychiatric populations. Brain Res Rev 13:371-389

Tariot PN, Cohen RM, Welkowitz JA, Sunderland T, New- 
house PA, Murphy DL, Weingartner H (1988): Multipledose arecoline infusions in Alzheimer's disease. Arch Gen Psychiatry 45:901-905

Thal LJ, Masur DM, Blau AD, Fuld PA, Klauber MR (1989): Chronic oral physostigmine without lecithin improves memory in Alzheimer's disease. J Am Geriatr Soc 37: 42-48

Wechsler DA (1955): Wechsler Adult Intelligence Scale. New York, Psychological Corporation
Whitehouse PJ, Price DL, Struble RG, Clark AW, Coyle JT, DeLong MR (1982): Alzheimer's disease and senile dementia: Loss of neurons in the basal forebrain. Science 215:1237-1239

Woolf NJ, Butcher LL (1991): The cholinergic basal forebrain as a cognitive machine. In Richardson RT (ed), Activation to acquisition: Functional aspects of the basal forebrain cholinergic system. Boston, Birkhauser, pp 347380 